\title{
Conflict scenario emotion events in reality television: a cross-cultural perspective
}

\author{
Paul A. Wilson
}

University of Łódź, Poland

\begin{abstract}
The present paper provides an analysis of an Indian female contestant and a British female contestant involved in an Emotion Event, conflict scenario in Celebrity Big Brother, a British reality television show that was aired by the Channel 4 television company. It was shown that the spoken communication between the two contestants conformed to the low context vs. high context communication cultures that are associated with collectivism and individualism, respectively. More specifically, whereas the more collectivistic Indian participant engaged in a more inferred, contextualised and implicit communication style, the style of communication of the British participant was characterised by a clear, logical, explicit message. Furthermore, in a typical individualistic response to the hurtful threat of shame, the British participant, in contrast to the Indian participant who demonstrated a more socially constructive response, employed a more aggressive, confrontational response strategy that was characterised by fight (Wilson, 2017) and relatively uncontrolled anger. This opposes the viewpoint that emotions are discrete entities that function independently of other emotions and supports a conceptual structure of emotions that is based on the proximity of emotion clusters (Wilson \& Lewandowska-Tomaszczyk, 2019)..
\end{abstract}

Key words: anger, collectivism, culture, Emotion Events, high context communication, Hinduism, individualism, low context communication, reality show, shame

\section{Introduction}

Abundant evidence shows that emotions do not translate well across languages. Many of these studies use different methodologies to provide contrastive analyses of cultural differences between emotion concepts (e.g., Wilson \& Lewandowska-Tomaszczyk, 2017; Lewandowska-Tomaszczyk \& Wilson, 2013). Other studies have shown that there are fewer differences in emotional expressions across cultures (e.g., Ekman \& Friesen, 1986). However, the inherent problems of objectivity mean that it is relatively more difficult to analyse emotion events from a cultural 
viewpoint. Analysing emotion events in television reality shows offers a possible greater approximation towards valid, objective interpersonal interaction within such events.

The present study analyses two female contestants (Jade Goody, a white British reality show celebrity and Shilpa Shetty, an Indian, Hindu Bollywood star) who interact in an Emotion Event, conflict scenario in Celebrity Big Brother, a British reality television show that was aired by the Channel 4 television company (2007). Within an Emotion Event scenario structure, the analysis is performed on the basis of two cultural dimensions - low context vs. high context communication (Hall, 1959) and collectivism vs. individualism (Hofstede, 1980). The central emotion in the analysis of the verbal exchange is shame, which is shown to elicit culture-specific instances of fight and flight, and associated emotions (Wilson, 2017). This is consistent with the viewpoint of a cluster representation of emotions in conceptual space (Wilson \& Lewandowska-Tomaszczyk, 2019).

\subsection{Emotion Events}

Emotions can be defined in terms of an Emotion Event, arising as a reaction to a stimulus. There are thus prototypical Emotion Event Scenarios and extended event scenarios. These extensions cover either peripheral scenarios or clusters of emotions, which can eventually lead to a blended Event Scenario. Mixed feelings, experiencing more than one emotion at the same time, i.e., emotion clusters, and the difficulty in identifying one particular emotion vis-à-vis another and experiencing a blended type of emotion instead are frequent departures from a prototype.

Biological, physiological and some psychological/cognitive properties can be identified along with prototypically accompanying scenarios by sophisticated questionnaires, applied to investigate emotions in a variety of languages and cultures (see analyses of English and Polish surprise, fear, joy, and happiness (Lewandowska-Tomaszczyk \& Wilson, 2010, 2013; Wilson, Lewandowska-Tomaszczyk, \& Niiya, 2013). On the basis of these variables we can propose a Prototypical Emotion Event Scenario, which covers the following constituents:

Context (Biological predispositions of Experiencer; Social and Cultural conditioning; On-line contextual properties of Event) [Stimulus $\rightarrow$ Experiencer \{(internally and externally manifested) physiological and physical symptoms; affective state + (internally experienced) Emotion $\} \rightarrow$ possible external reaction(s) of Experiencer (blending; language: metaphor; emotion and emotional talk; non-verbal reactions)] 


\subsection{Culture: Collectivism versus Individualism}

\section{Collectivism}

The fundamental feature of collectivism is the closer interpersonal relationships that are present within groups, which result in these groups being more cohesive. Individuals within these groups have a greater obligation to fulfil their responsibilities towards other group members (Oyserman et al., 2002). The social, interconnected ties within the in-group are more important than the individual, autonomous functioning of the person within that group (Triandis, 1995). Consistent with the more social elements of collectivism, self-concept is based on group membership (Hofstede, 1980), and includes characteristics such as the sacrifice of the self for others and common goals, as well as the maintenance of good relations (Markus \& Kitayama, 1991). Well-being for the collectivist is determined by successful performance in social roles and the completion of duties (Markus \& Kitayama, 1991). Emphasis is placed on the achievement of in-group harmony by controlling the outward expression of emotions.

\section{Individualism}

In individualistic cultures one perceives oneself as an individual, autonomous entity and there is less emphasis placed on one's relationships with others. The various accounts of individualism share the fundamental features of more of an individualised construal of goals, uniqueness and control (Oyserman et al., 2002). Highlighting the personal autonomy associated with individualism, Hofstede (1980) views the inclusion of self-fulfilment and personal accomplishments in one's identity, the importance of rights in comparison with duties, and a focus on oneself and immediate family as central features. In contrast with collectivistic individuals who have relatively more interdependence within their in-groups (e.g., family, nation), individualists show a greater degree of independence from their in-groups, which is evidenced in the importance they place on personal goals in comparison with the goals of their in-groups. Consistent with Schwarz's (1990) emphasis on the importance of individualistic status achievement, Triandis (1995) observes the negotiation of duties within social relationships. Individualists regard the formation of a positive self-concept as a fundamental personal characteristic that they closely associate with personal achievement.

\section{Low Context vs. High Context Communication Cultures}

It was the work of Hall (e.g., 1959) that initially highlighted the importance of low context vs. high context communication styles across cultures. Communication style denotes the way in which individuals express themselves when 
communicating with others and specific patterns have been observed that are prototypical for certain cultures. With respect to the present study, whereas India has traditionally been identified as a high context culture (Nishimura, Nevgi \& Tella, 2008), Britain is regarded as a low context culture.

\section{High Context Communication Cultures}

In high context cultures very little information is explicitly conveyed in the coded, verbal part of the message. In contrast, most of the meaning of the message is present in the physical context or internalised in the individual. Self-construals are based on interdependence relationships that place emphasis on connectedness and harmony through the high regard for the actions, feelings and thoughts of others in social relationships. The message recipient is responsible for gaining insight into the contextual or hidden meaning of the message. Less emphasis is placed on direct, explicit messages and the verbal content is deemed an inherent, inseparable part of the whole communication context. Relatively less importance is placed on conveying a clear verbal message. It is important for the recipient of the message to detect implicit and subtle contextual cues when attempting to gain an understanding of the communication. In the absence of such context, the interlocutor's message might be regarded to be pointless and possibly deceitful.

\section{Low Context Communication Cultures}

As meaning is expressed in an explicit verbal code in low context cultures, the recipient of the message expects the sender to give a detailed message, be direct, and use language that is not ambiguous. On the basis of the emphasis placed on privacy, autonomy and independence, there is more freedom to express oneself and be direct. It is the sender of the message who is often responsible for misunderstanding or miscommunication as they are expected to present direct, clear, unambiguous information that the recipient can easily decode. Consistent with this, greater value is placed on rational, logical and analytical thinking. In order that the listener can completely understand the meaning of the message the speaker is primarily responsible to express ideas and thoughts with utmost clarity.

\subsection{Shame}

\section{The Nature of Shame}

The features of shame make this self-conscious, moral emotion a key element of human interaction. One of the main reasons for shame being an important self-conscious emotion is that it is characterised by negative criticism of the global 
self (Lewis, 1971) and is therefore related to evaluations of self-worth and self-esteem. The central features pertaining to this global self include acceptance or rejection by others, self-regulation and self-evaluation. It is clear that such criticism involving the global self is more likely to be more threatening as damage to the very essence of one's being is at stake. Shame is further characterised by fear of this damage or criticism to the global self (Kam \& Bond, 2008). Such involvement of the global self can be seen more clearly when one compares it with guilt, which is another self-conscious emotion, but one that is typically less hurtful than shame as the main focus is on behaviour, not one's core self, and hence one's self-worth and self-esteem are less threatened (Tangney \& Tracy, 2012). Ogarkova, Soriano, \& Lehr (2012) observe that shame is elicited in response to the violation of an important social standard in which the transgressor is concerned with others' actual or imagined evaluations, which might lead to external sanctions. The feeling of being small and the desire to avoid being seen by others lead to avoidance and withdrawal behaviours. Shame is more of an intense emotion than guilt and is associated with feelings of weakness, powerlessness and helplessness. The tendency to hide, withdraw and disappear, and feelings of powerlessness associated with shame are consistent with two of the four approaches to shame outlined by Fontaine et al. (2006). Shame, unlike guilt, is also not characterised by an emphasis on reparations or penance (Ogarkova, Soriano, \& Lehr, 2012). Finally, shame can lead to aggressive behaviour (Scheff, 2014).

\section{Shame the Master Emotion}

The prominence of shame as one of the most, if not the most, important emotion in our lives can be witnessed in its unique function in social relationships due to its psychological and social importance, which has led to it being labelled a master emotion. This status is warranted on the basis of a number of features, not least on account of its relationship with a wide range of other emotions, including anger and aggression, fear, anxiety, sadness and depression, hurt, and compassion. Poulson (2000) additionally deems envy, jealousy, disgust, happiness, pride, relief, hope and love to be related to shame.

To gain an understanding of the possible mechanisms underlying the influence of shame on emotions in its closest proximity one needs to understand how physical threats and the threat of social exclusion are both associated with affective pain. MacDonald \& Leary (2005) argue that "the aversive emotional state of social pain is the same unpleasantness that is experienced in response to physical pain" (p. 203). They further propose that one is motivated to avoid possible situations that threaten social exclusion through the feelings of 
pain that they are often coupled with in a similar way in which one learns to avoid physical threats. The role of shame in socially threatening situations is highlighted by Dickerson, Gruenewald \& Kemeny (2004), who identify shame and the physiological activity that accompanies it as a fundamental underlying emotional response to such threats in the same way that, for example, fear and its physiological responses occur when one is physically threatened. To summarise, shame can be viewed as an emotional response to social pain that is equivalent to the unpleasant emotional states that are elicited by situations involving physical pain and threat.

The emotions that derive from the affective pain that accompanies threats to the preservation of one's social self, and hence shame, are similar to those emotions that have been widely documented to arise from the affective pain associated with physical threat. Furthermore, the social pain that underlies shame and physical pain elicit the same mechanisms to defend against such threats, namely fight, flight and fright responses (Elison, Garofalo, \& Velotti, 2014). ${ }^{1}$

\section{Collectivistic vs. Individualistic Shame}

As argued by Lewandowsks-Tomaszczyk \& Wilson (2014), in collectivistic cultures that place more emphasis on interpersonal harmony, one would expect relatively more withdrawal tendencies associated with shame. Consistent with this, Wallbott \& Scherer (1995), in a large-scale cross-cultural study involving participants from 37 countries who were required to describe instances in which they had experienced emotions including shame and guilt, observed that in collectivistic cultures shame adheres more closely to the general shame profile, which includes the feature of withdrawal. With an individualistic-collectivistic score of 48, (Hofstede, https://www.hofstede-insights.com/product/compare-countries/), one would expect individuals from India to conform to this pattern relatively more than the British (score 89). However, in terms of the present study it is also pertinent to focus on more specific features of Shilpa Shetty than global collectivism. In this respect, a significant feature is her Hindu faith, particularly as Croucher et al. (2011) observes that Female Indian Hindus are more likely to prefer avoiding, compromising, integrating, and obliging conflict styles than female Indian Muslims.

To sum up, there is evidence to suggest that Shilpa Shetty, on account of both her collectivistic and Hindu background might have a tendency towards avoidance and compromise in situations involving shame and conflict.

1 Elison, Garofalo, \& Velotti (2014) prefer to use the term freeze instead of fright. However, these are equivalent and the term used in the present paper is fright. 
A key issue with regard to the present focus of study is the possible greater anger that this emotion appears to generate in individualistic cultures. Scheff (2014) observes that it is the hidden shame that is characterised by elements of anger and violence that is more salient in individualistic cultures. It is the emphasis on achievement in individualistic societies that fosters an element of alienation and because there is an expectation that one will attain a sense of individual completeness, the shame that arises from the failure to meet this expectation is more likely to be hidden. Such instances of hidden, unresolved shame can accumulate and lead to resentment, anger and outbursts of violence. On the basis of this, one would expect Jade Goody to exhibit relatively more anger in response to her possible experiences of shame.

\subsection{Aims}

A comparative analysis of an Emotion Event scenario involving Jade Goody and Shilpa Shetty is performed to determine whether they conform to expectations based on individualistic/low context communication culture vs. collectivistic/ Hindu/high context communication culture, respectively.

\section{Analysis of Big Brother Emotion Event Scenario}

\subsection{Background}

The Emotion Event scenario is present in an unedited video excerpt from Celebrity Big Brother 5 (2007) that lasts for 9 minutes and 24 seconds (published on YouTube on $17^{\text {th }}$ February, 2010, https://www.youtube.com/ watch? $\mathrm{v}=$ P7WHd9PUL5w). At the beginning of the video clip, three housemates, including Jade Goody are sitting on sofas in the lounge, which, in an open-plan design, is attached to the kitchen area. Shilpa Shetty is in the kitchen area and asks the other three housemates where the chicken stock is, to which they answer that there is one left. Shilpa expresses surprise that they had used most of the chicken stock cubes in a previous meal as they had been only supposed to use one of the stock cubes for the meal. In an argument that ensues Jade Goody seems to take offence at the apparent accusation of wasting the chicken stock and retaliates with the accusation that on a previous recent occasion Shilpa cooked chicken that was left uneaten and therefore wasted because it was not cooked properly. 


\subsection{Collectivistic vs. Individualistic Shame}

This part of the analysis of the interaction between Jade and Shilpa identifies possible shame responses and other possible emotions that are elicited as a consequence of this.

\section{Jade - an Individualistic Sense of Shame}

Shilpa (1 minute, 7 seconds): "you require one (chicken stock cube) for that much pasta." Jade (2 minutes, 22 seconds): "get over it, three cubes, OK Shilpa it was three cubes, but the other day there was a whole chicken that went to waste because it was pink."

From this response from Jade it can be deduced that she views Shilpa's comment regarding the excessive use of chicken stock cubes as a personal attack. As outlined above, such a personal attack is central to shame. The response is an attempt to deflect this perceived attack with an accusation of her own directed towards Shilpa. This is consistent with the above discussion regarding the fight that characterises individualistic shame.

Later in the Emotion Event scenario, there is much more direct evidence that Jade views Shilpa's comments as a personal attack:

Jade ( 3 minutes, 43 seconds): "So what? I ate an OXO cube. Shoot me in my pissing head." Jade (4 minutes, 37 seconds): "I've ate two fucking OXO cubes. Stab my gut open and pull it out."

From these comments, it can be understood that Jade feels victimised and punished by Shilpa for using too much chicken stock. However, rather than her reaction remaining within the sphere of her actions, it permeates deeper to the core of her being and is clearly hurtful. In this sense, it is an elicitor of shame. The hurt that Jade appears to feel is in agreement with what one would expect from an individualistic individual.

Consistent with expectations pertaining to the fight and anger that can arise especially from an individualistic variant of shame, Jade expresses a clear sense ofanger - (4 minutes, 12 seconds): "I feel furious."

\section{Shilpa - a Collectivistic Sense of Shame}

During the confrontational interaction with Jade, Shilpa is the target of a personal attack by Jade. 
Jade (5 minutes, 14 seconds): "Shilpa, you didn't only order OXO cubes, that was really stupid to say."

Shilpa (5 minute, 30 seconds): "Jade, I don't want to fight. You want to get argumentative. It's fun for you, please go on be my guest. I don't want to do that, it's not my style."

In contrast with the fight response by Jade to what she perceived to be a hurtful attack by Shilpa, we can see that Shilpa has a different response to what can be deemed an equivalently hurtful attack by Jade. Specifically, consistent with a fundamental principle of collectivism pertaining to the maintenance of interpersonal harmony, Shilpa explicitly expresses a desire to refrain from fighting. Such reticence can also be viewed as withdrawal, which is another characteristic feature of collectivistic shame.

Jade (5 minutes, 44 seconds): "You're pathetic. You're pathetic. You're pathetic. You're absolutely pathetic."

.....: "( 6 minutes 43 seconds): Shilpa, in all fairness, you said the only thing I ordered off of the whole shopping list was OXO cubes."

Shilpa (6 minutes, 50 seconds): "I take that back. That was one of the things that I ordered. That is what I meant to say."

In these verbal exchanges, the intensity of the attack from Jade not only increases but can be deemed more central to the concept of shame as referring to an individual as pathetic is a central attack on one's core self. Despite this, Shilpa reinforces her withdrawal tendency with the words "I take that back," which is again consistent with her collectivistic background.

\subsection{Low Context vs. High Context Communication}

This part of the analysis of the interaction between Jade and Shilpa identifies the possible low context communication of the former and the high context communication of the latter.

\section{Jade - Low Context Communication}

There is a great deal of evidence that Jade adopts a low context communication style in her interaction with Shilpa. This is mainly manifested in her accusation that Shilpa is lying. This accusation is based on Shilpa's initial comment that the only food item that she ordered from the Big Brother authorities in the most recent food order was OXO chicken stock cubes: 
Shilpa (1 minute, 13 seconds): "It's the only thing I had ordered Shilpa (1 minute, 29 seconds): It's the only thing I ordered the last time."

Jade (5 minutes, 14 seconds): "Shilpa, you didn't only order OXO cubes, that was really stupid to say."

This comment by Jade is typical of low context communication as it focuses on the truth value of Shilpa's statement. There is more evidence for this later, as she is adamant that Shilpa should admit her falsehood:

Jade (5 minutes, 27 seconds): "You did not say I only ordered OXO cubes ... Did you say that?"

Jade (5 minutes, 39 seconds): "Did you say I only ordered OXO cubes?"

Typical of an individual from a low-context culture, we can later learn from Jade's direct accusations, which she expresses with unrestrained shouting, how important it is for her to receive a truthful message:

Jade (6 minutes, 24 seconds): "You did not only pick OXO cubes off the shopping list, so you're a liar. Not only are you a fake, you're a liar."

Jade (8 minutes, 01 second): “You're a liar. You're a liar and you're a fake. You're a liar!"

\section{Shilpa - High Context Communication}

In Shilpa's responses to the accusations that she has been lying, she shows evidence that she is a high context communicator:

Shilpa (5 minutes, 24 seconds): "I didn't say I ordered them, I only asked if you used them."

Shilpa (6 minutes, 50 seconds): "I take that back. That was one of the things that I ordered. That is what I meant to say."

It appears that what Shilpa is saying here is that her earlier statement that she had only ordered OXO chicken stock cubes was not the full intention of her message. With her later response that the intention of this message was that it was one of the things she ordered and that she had only wanted to know if anyone had used them, we can see that she had not initially delivered a direct, explicit message. Consistent with the high context communication style, her initial message implicitly alluded to a hidden meaning, which she expected her interlocutor to decipher from the whole communication context. 


\section{Discussion and Conclusions}

Consistent with predictions, the analysis of the main interactants in an Emotion Event scenario in a Big Brother setting shows that whereas Shilpa Shetty, an Indian Hindu participant, exhibited a withdrawal style that was additionally characterised by high context communication, Jade Goody engaged in a more expressive fight strategy and revealed a low context communication style preference.

With respect to shame, the two contestants demonstrated responses that are in agreement with expectations on the basis of their respective cultural identities. The relatively greater withdrawal style adopted by Shilpa in response to the probable shame that she experiences as a consequence of Jade's verbal accusations is consistent with observations of withdrawal in previous studies on shame. Shilpa's apparent concern for social harmony is also consistent with her cultural background. In contrast, the fight strategy adopted by Jade as a consequence of her apparent experience of shame is in accordance with an individualistic response. Furthermore, the hurt that she demonstrates points to an autonomous individual whose core self has been criticised. With respect to the cluster approach to emotion concepts outlined above, Jade's anger response confirms the relatively close proximity of the shame and anger in conceptual space, especially in individualistic cultures.

The evidence that the two contestants conformed to expectations with respect to low context and high context culture styles is based on conflicting views of the veracity of Shilpa's statement regarding her food order from the Big Brother authorities. Recall that Shilpa later admitted that her initial statement that the OXO cubes chicken stock was the only item that she had ordered from the Big Brother authorities was not true. Jade, being an individual from a low context communication culture, highlights the lack of truth in Shilpa's statement and demonstrates the value she places on receiving a clear, direct, explicit, truthful message. In contrast, Shilpa conforms to what one would expect from a typical high context communicator as she appears to imply other, indirect, information in her message that she expects her interlocutor to decode and understand. In this respect, the interaction between Jade and Shilpa can be considered a good example of possible misunderstandings that can arise when individuals from low and high context cultures communicate.

The difficulty in gaining objective assessments of emotions via observations of interactants should not be underestimated. A main issue in this respect is observer bias, in which the participants are conscious of being observed and are therefore less likely to behave naturally. It is difficult to imagine a situation in which individuals are observed without their prior knowledge, especially when one must consider the personal rights of those concerned. While Big Brother contestants are 
aware that they are being observed and will possibly be conscious that by behaving in certain ways they will lose or gain the support of the audience, it could be argued that over the weeks that they are in the Big Brother environment they will become more accustomed to the environment and behave in a way that is more consistent with their natural behaviour.

The present study should be viewed as an initial attempt to analyse Emotion Event scenarios in a reality show context and as such it offers a limited scope. This notwithstanding, the analyses demonstrate effects that are consistent with those obtained from a number of different paradigms. The methodology has the potential to be expanded to study Emotion Events that centre on different emotions across a wide range of cultures.

\section{References}

Croucher, S. M., Holody, K. J., Hicks, M. V., Oommen, D., \& DeMaris, A. (2011). An examination of conflict style preferences in India. International Journal of Conflict Management, 22(1), 10-34.

Dickerson, S. S., Gruenewald, T. L., \& Kemeny, M. E. (2004). Psychobiological responses to social self threat: Functional or detrimental. Self and Identity, 8, 270-285.

Ekman, P. \& Friesen, W. V. (1986). A new pan-cultural facial expression of emotion. Motivation and Emotion, 10(2), 159-167.

Elison, J., Garofalo, C., \& Velotti, P. (2014). Shame and aggression: Theoretical considerations. Aggression and Violent Behavior, 19, 447-453.

Fontaine, J. R. J., Luyten, P., De Boeck, P., Corveleyn, J., Fernandez, M., Herrera, D., Ittzès, A., \& Tomcsányi, T. (2006). Untying the Gordian Knot of guilt and shame: The structure of guilt and shame reactions based on situation and person variation in Belgium, Hungary, and Peru. Journal of Cross-Cultural Psychology, 37(3), 273-292.

Hall, E. (1959). The Silent Language. New York: Doubleday.

Hofstede, G. (1980). Culture's Consequences: International Differences in Work-related Values. Beverly Hills: Sage.

Hofstede, G. https://www.hofstede-insights.com/product/compare-countries

Kam, C. C-S., \& Bond, M. H. (2008). Role of emotions and behavioural responses in mediating the impact of face loss on relationship deterioration: Are Chinese more face-sensitive than Americans? Asian Journal of Social Psychology, 11, 175-184.

Lewandowska-Tomaszczyk, B., \& Wilson P. A. (2010). A contrastive perspective on emotions: surprise. Review of Cognitive Linguistics, 8(2), 321-350.

Lewandowska-Tomaszczyk, B., \& Wilson P. A. (2013). English fear and Polish strach in contrast: GRID approach and Cognitive Corpus Linguistic Methodology. In J. Fontaine, K. R. Scherer \& C. Soriano (Eds.), Components of Emotional Meaning: A Sourcebook, (pp. 425-436). Oxford: OUP. 
Lewandowska-Tomaszczyk, B., \& Wilson P. A. (2014). Self-conscious emotions in collectivistic and individualistic cultures: a contrastive linguistic perspective. In J. Romero-Trillo (Ed.), Yearbook of Corpus Linguistics and Pragmatics 2014: New Empirical and Theoretical Paradigms, (pp. 123-148). Berlin: Springer.

Lewis, H. B. (1971). Shame and Guilt in Neurosis. New York: International Universities Press.

MacDonald, G., \& Leary, M. R. (2005). Why does social exclusion hurt? The relationship between social and physical pain. Psychological Bulletin, 131(2), 202-223.

Markus, H. R., \& Kitayama S. (1991). Culture and the self: Implications for cognition, emotion, and motivation. Psychological Review, 20, 568-579.

Nishimura, S., Nevgi, A., \& Tella, S. (2008). Communication style and cultural features in high/low context communication cultures: A case study of Finland, Japan and India. In A. Kallioniemi (Ed.), Renovating and Developing Subject Didactics. Proceedings of a Subject-didactic Symposium in Helsinki on Feb. 2, 2008. Part 2, (pp. 783-796). University of Helsinki. Department of Applied Sciences of Education. Research Report 299.

Ogarkova, A., Soriano, C., \& Lehr, C. (2012). Naming feeling: Exploring the equivalence of emotion terms in five European languages. In P. A. Wilson (Ed.), Dynamicity in Emotion Concepts. Lodz Studies in Language, Volume 27, (pp. 253-284). Frankfurt a. Main: Peter Lang.

Oyserman, D., Coon, H. M., \& Kemmelmeier M. (2002). Rethinking individualism and collectivism: evaluation of theoretical assumptions and meta-analysis. Psychological Bulletin, 128, 3-72.

Poulson, C. (2000). Shame: The master emotion? University of Tasmania, School of Management Working Paper Series, (20-03), 1-43.

Scheff, T. J. (2014). The ubiquity of hidden shame in modernity. Cultural Sociology, 8(2), $129-141$

Schwartz, S. H. (1990). Individualism-collectivism: Critique and proposed refinements. Journal of Cross-Cultural Psychology, 21, 139-157.

Tangney, J. P., \& Tracy, J. L. (2012). Self-conscious emotions. In M. R. Leary \& J. P. Price (Eds.), Handbook of Self and Identity (2nd ed.), (pp. 446-478). New York: The Guilford Press.

Triandis, H. C. (1995). Individualism and Collectivism. Boulder, CO: Westview Press.

Wallbott, H., \& Scherer, K. (1995). Cultural determinants in experiencing shame and guilt. In J. Tangney \& K. Fischer (Eds.), Self-conscious Emotions, (pp. 465-487). New York: Guilford Press.

Wilson, P. A. (2017). The Role of shame in conflict: A cross-cultural perspective. In B. Lewandowska-Tomaszczyk, P. A Wilson, \& S. M. Croucher (Eds.), Approaches to Conflict: Theoretical, Interpersonal, and Discursive Dynamics, (pp. 55-78). Lanham, Maryland: Lexington Books.

Wilson, P. A., \& Lewandowska-Tomaszczyk, B. (2017). Pride in British English and Polish: Contrastive linguistic perspective. In F. Sharifian (Ed.), Advances in Cultural Linguistics, (pp. 247-288). Cham: Springer. 
Wilson, P. A., \& Lewandowska-Tomaszczyk, B. (2019). Cognitive structure and conceptual clusters of emotion terms. Filozofia i Nauka, 7(1), 91-123.

Wilson, P. A., Lewandowska-Tomaszczyk, B., \& Niiya Y. (2013). Happiness and contentment in English and Polish: GRID and cognitive corpus linguistics. In J. Fontaine, J. Scherer, \& C. Soriano (Eds.), Components of Emotional Meaning: A Sourcebook, (pp. 477-481). Oxford: OUP. 